Supporting Information

\title{
Anionic Polymerization of Oxadiazole-containing 2- \\ Vinylpyridine by Precisely Tuning Nucleophilicity and the \\ Polyelectrolyte Characteristics of the Resulting Polymers
}

Andrew Goodwin, ${ }^{1}$ Kimberly M. Goodwin, ${ }^{l}$ Weiyu Wang, ${ }^{l}$ Yong-Guen Yu, ${ }^{2}$ Jae-Suk Lee, ${ }^{2, *}$ Shannon M. Mahurin, ${ }^{3}$ Sheng Dai, ${ }^{1,3}$ Jimmy W. Mays, ${ }^{1,3}$ and Nam-Goo Kang ${ }^{1, *}$

${ }^{1}$ Department of Chemistry, University of Tennessee, Buehler Hall 1420 Circle Dr. Knoxville, TN 37996, USA

${ }^{2}$ School of Materials Science and Engineering, Gwangju Institute of Science and Technology (GIST), 123 Cheomdangwagi-ro, Buk-gu, Gwangju 61005, Korea

${ }^{3}$ Chemical Sciences Division, Oak Ridge National Laboratory, Oak Ridge, TN 37831, USA

*Email: jslee@gist.ac.kr (J.-S.L)

*E-mail: nkang1@utk.edu (N.-G.K.) 


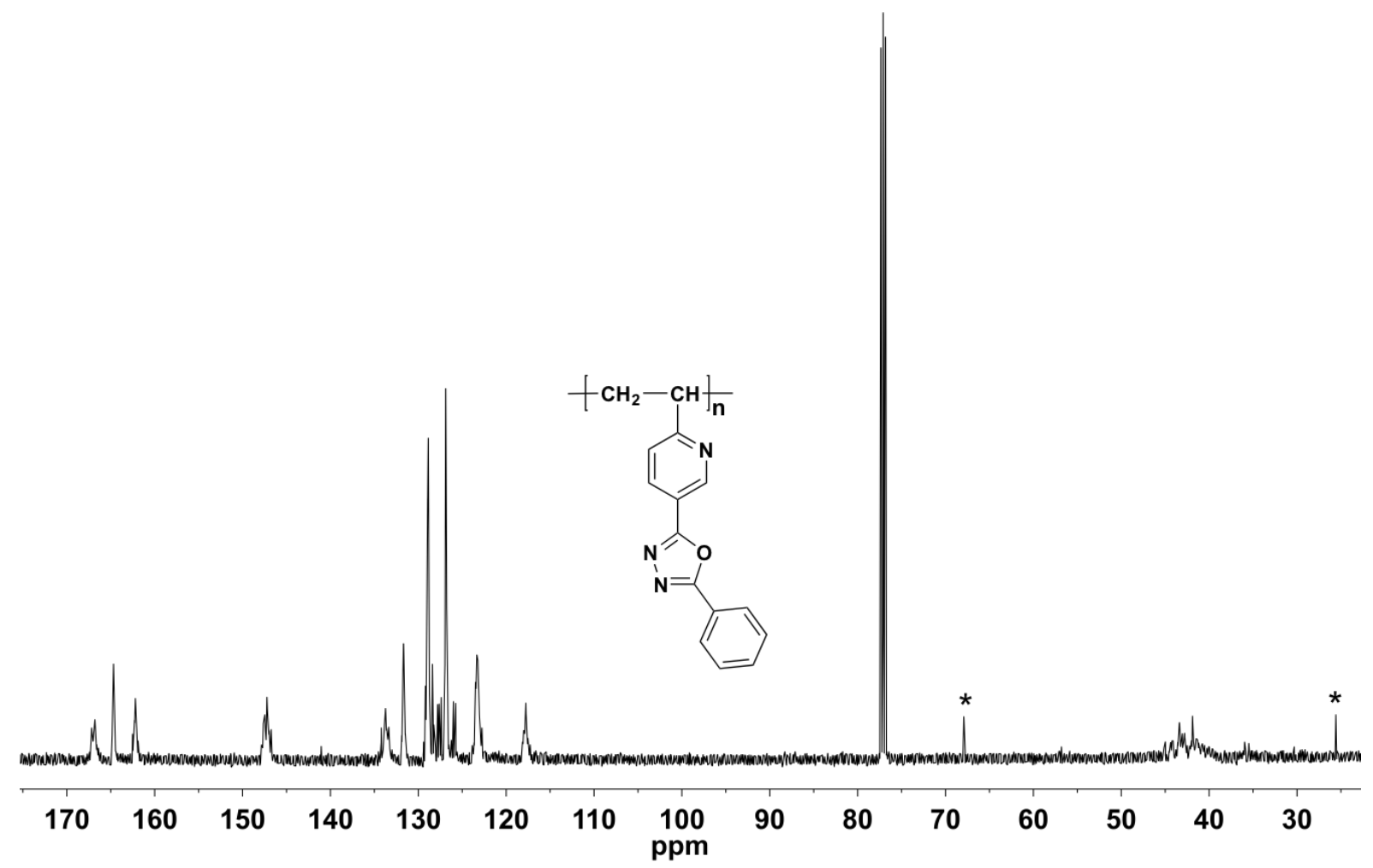

Figure S1. ${ }^{13} \mathrm{C}-\mathrm{NMR}$ spectra of $\mathrm{PVPyOzP}$ using $\mathrm{CDCl}_{3}$. Denoted by $*$ is tetrahydrofuran (THF) solvent. 

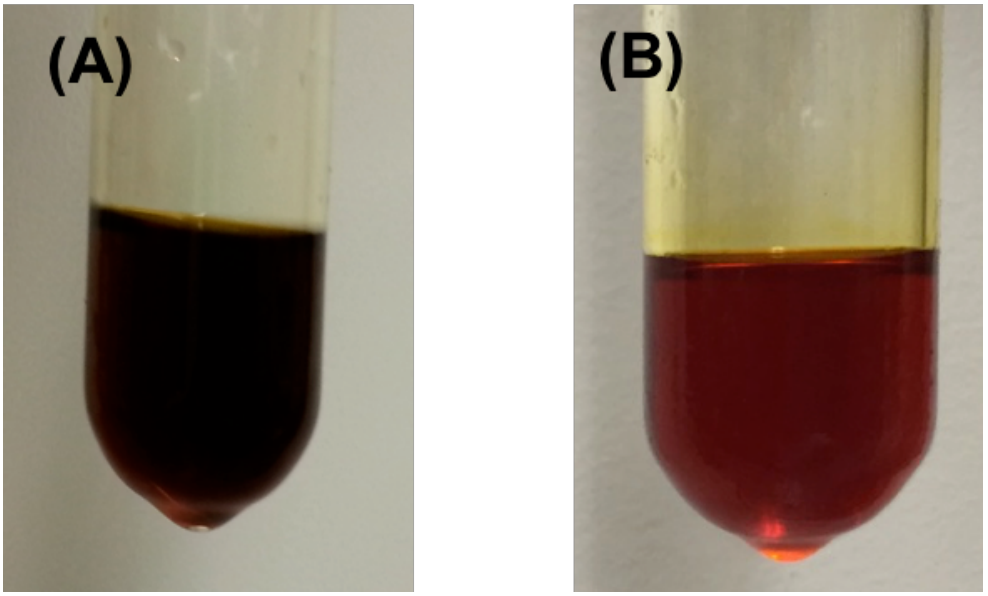

Figure S2. The polymeric solution of PVPyOzP synthesized via anionic polymerization using (A) only TPM-K (shown in the main manuscript) and (B) TPM-K/ZnEt ${ }_{2}$ and TPM$\mathrm{K} / \mathrm{BEt}_{3}$ in $\mathrm{THF}$ at $-78{ }^{\circ} \mathrm{C}$. 


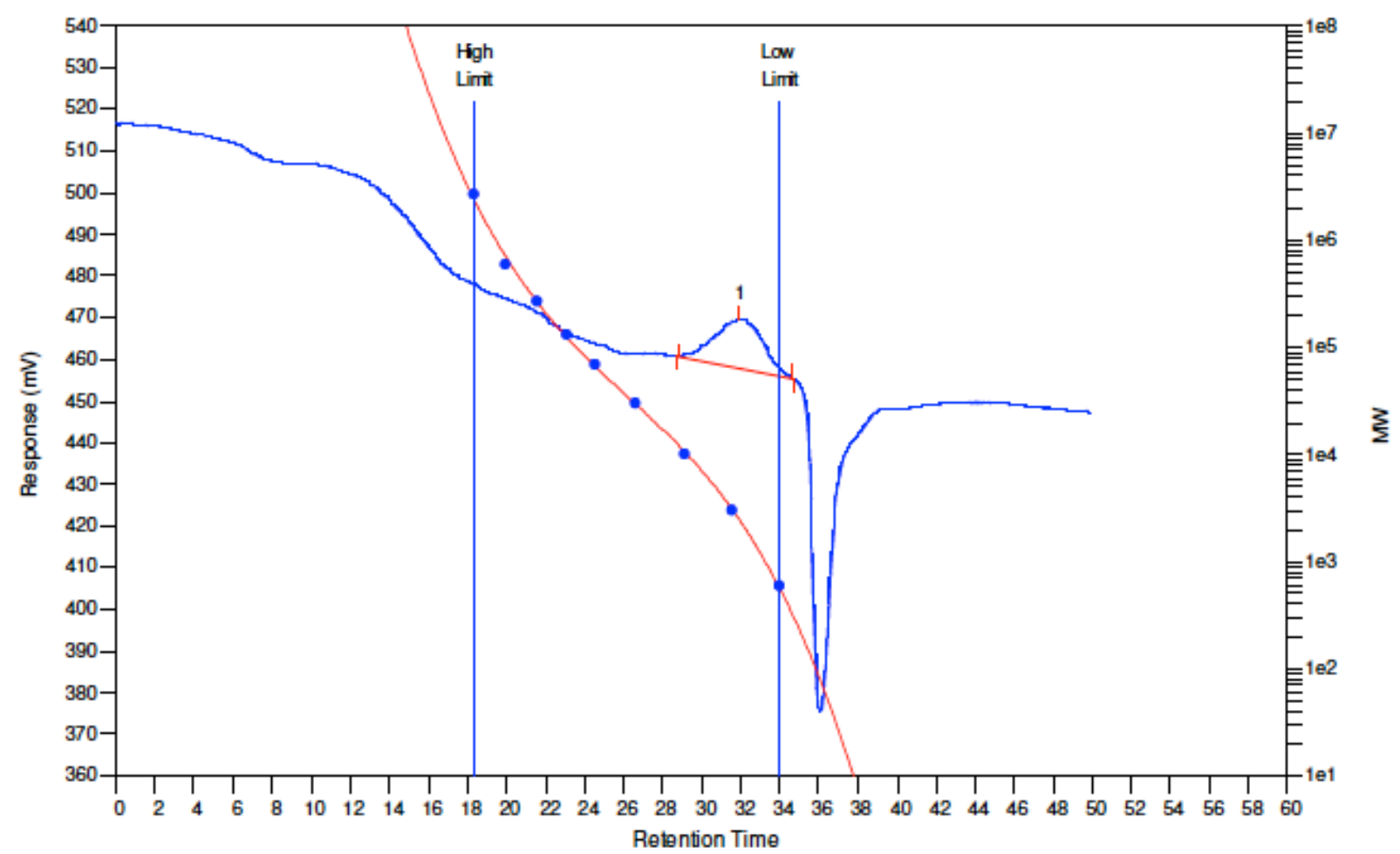

Figure S3. GPC curve of PVPyOzP using TPM-K/ZnEt $2(\mathrm{Mn}=2,200 \mathrm{~g} / \mathrm{mol}$ and PDI = 1.54). 


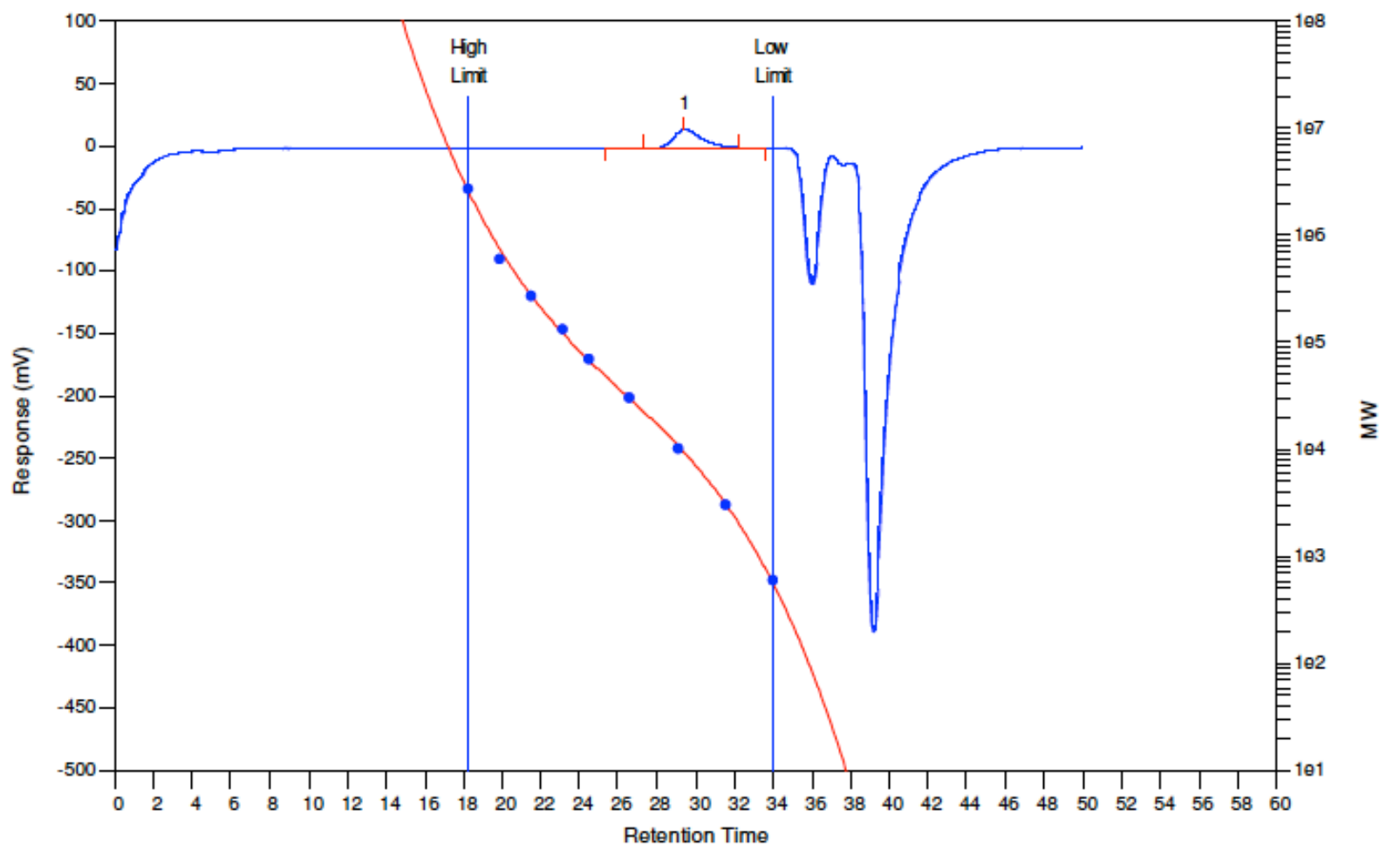

Figure S4. GPC curve of PVPyOzP using TPM-K/BEt $3(\mathrm{Mn}=7,500 \mathrm{~g} / \mathrm{mol}$ and PDI = 1.19). 

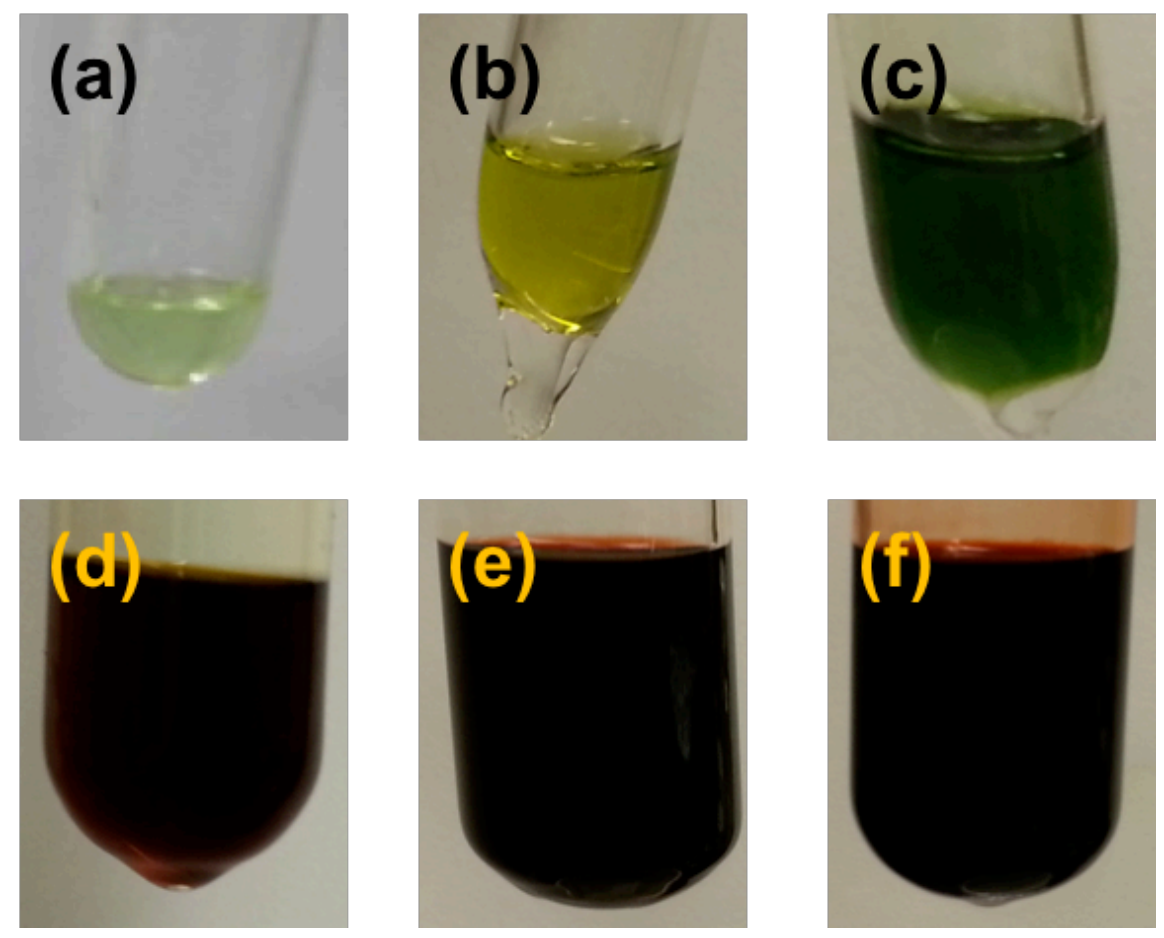

Figure S5. Solution colors of living PMMA and living PMMA- $b$-PVPyOzP; (a) living PMMA and (d) living PMMA- $b$-PVPyOzP of Entry 04, (b) living PMMA and (e) living PMMA- $b$-PVPyOzP of Entry 05, and (c) living PMMA and (f) living PMMA- $b$-PVPyOzP of Entry 06 in Table 3. 
(a)

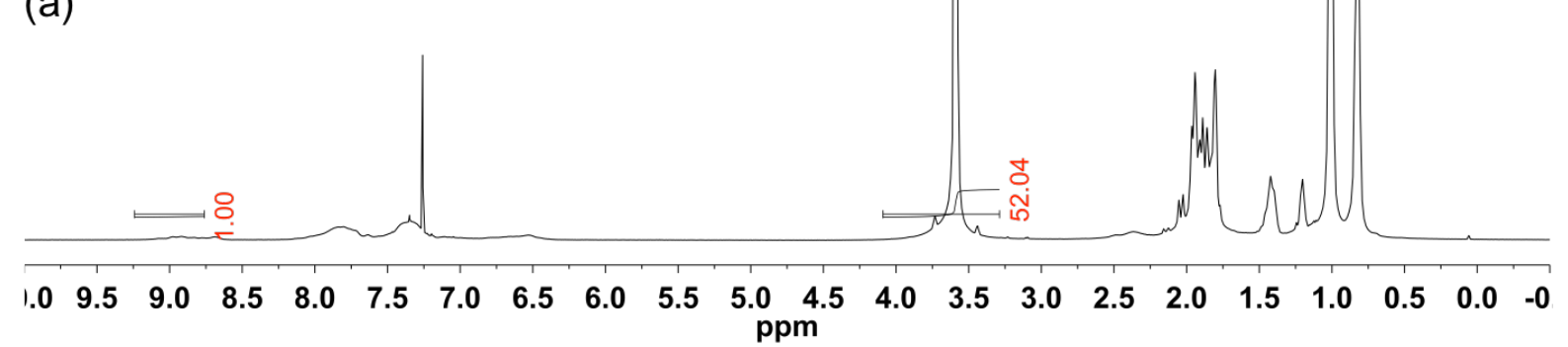

(b)
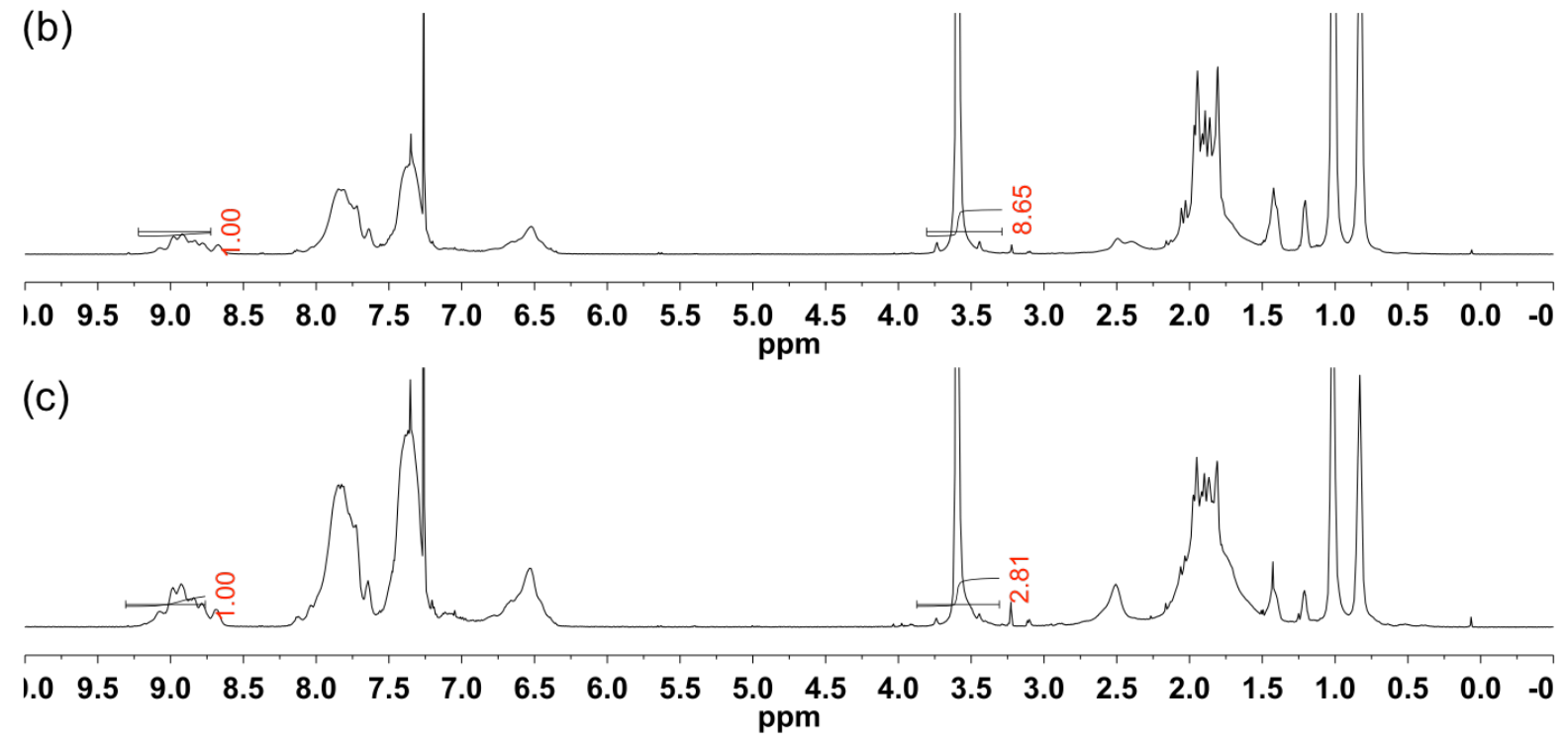

Figure S6. $\quad{ }^{1} \mathrm{H}-\mathrm{NMR} \quad$ spectra of poly(methyl methacrylate)-b-poly(2-phenyl-5-(6vinylpyridin-3-yl)-1,3,4-oxadiazole) (PMMA- $b$-PVPyOzP) with molar ratio of (a) 1:17.35, (b) 1:2.88, and (c) 1:0.93 (Entry 04, 05, and 06 in Table 1). 

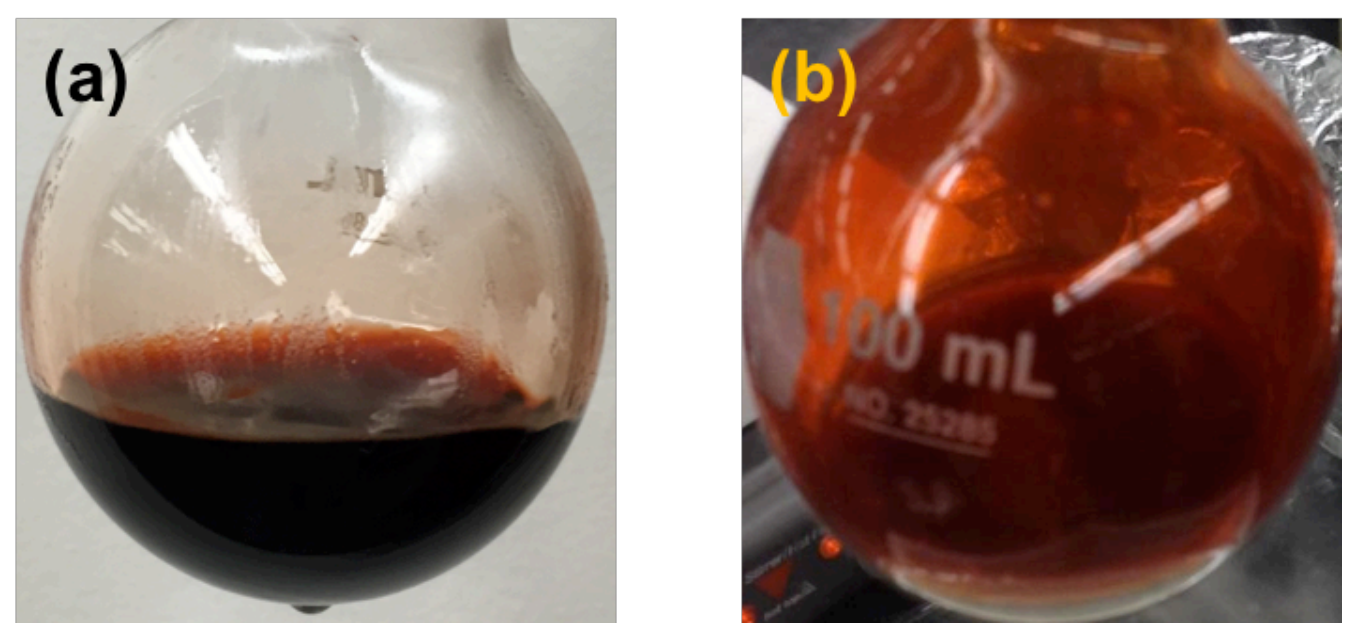

Figure S7. Solution color of (a) living PVPyOzP and (b) living poly(2-Phenyl-5-(6vinylpyridin-3-yl)-1,3,4-oxadiazole)- $b$-polyacrylonitrile (PVPyOzP- $b$-PAN) of Entry 07 in Table 3 . 


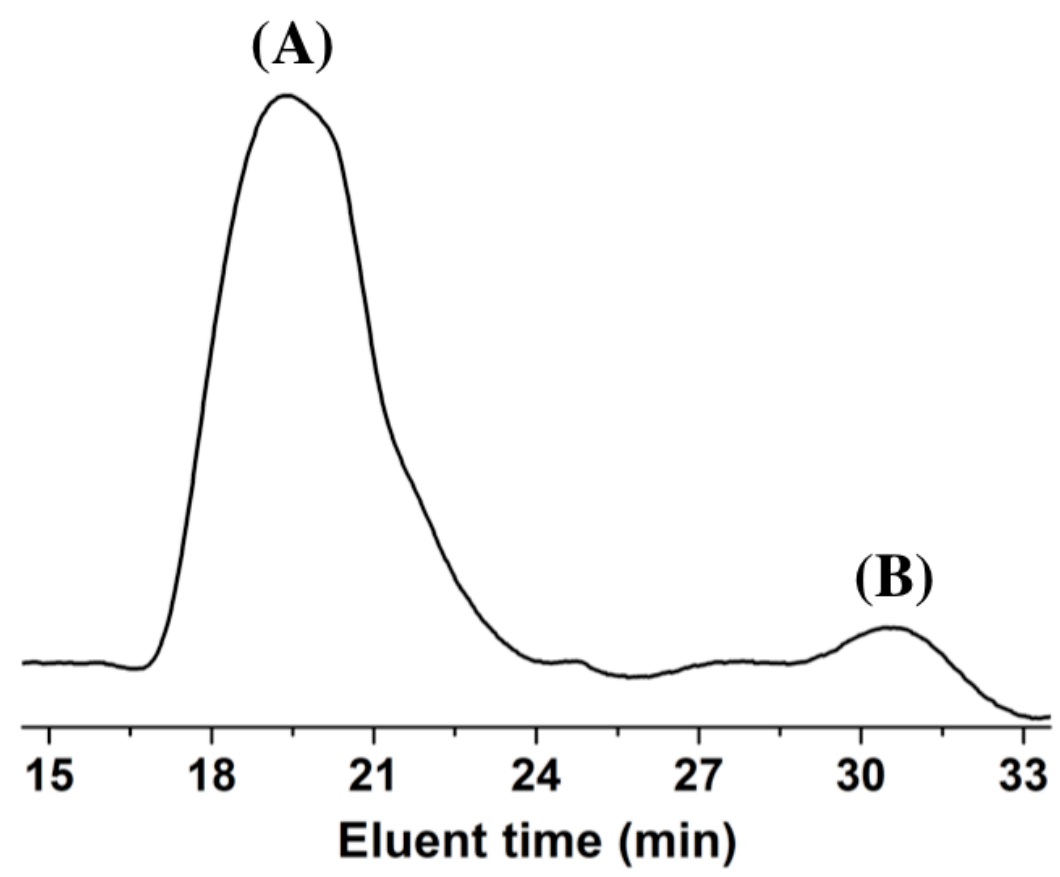

Figure S8. SEC curve of (A) PVPyOzP- $b$-PAN block copolymer with $\mathrm{Mn}=788,000 \mathrm{~g} / \mathrm{mol}$ and PDI $=1.41$ and (B) remaining PVPyOzP homo polymer with $\mathrm{Mn}=5,200 \mathrm{~g} / \mathrm{mol}$ and PDI = 1.19 in PVPyOzP- $b$-PAN. (Entry 07 in Table 3).

The above SEC was run on a Waters system consisting of a Waters model 510 pump, a Rheodyne model 7725(i) injector with a Knauer Smartline model 2300 RI detector. DMF + $0.1 \mathrm{M} \mathrm{LiBr}$ was used as the mobile phase in the following column set: four PSS (Polymer Standards Service) GRAM; 8x300 mm; 10 $\mu \mathrm{m} ; 100,1000$, and $3000 \AA$ along with an 8x50, $10 \mu \mathrm{m}$ guard. The instrument was calibrated with a set of PS standards in the molecular weight range of 600 to $7,500,000 \mathrm{~g} / \mathrm{mol}$. 


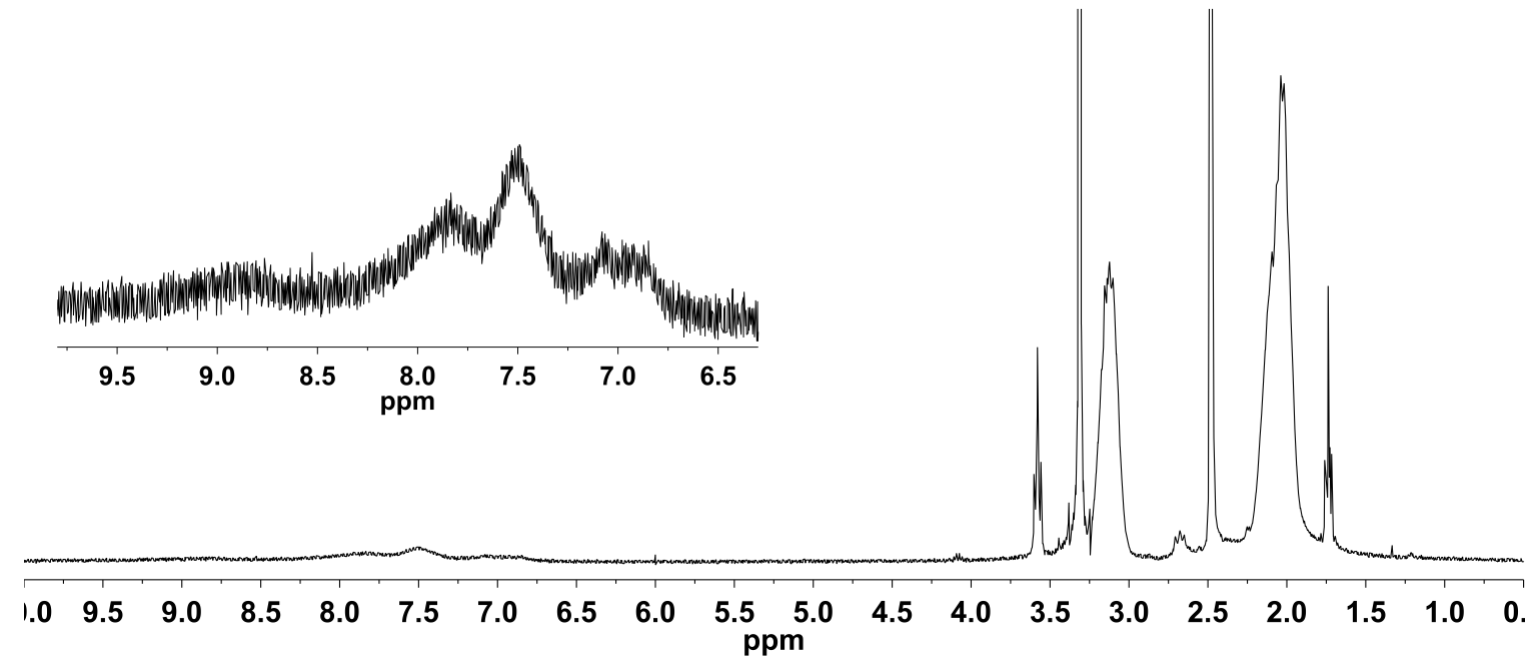

Figure S9. ${ }^{1} \mathrm{H}-\mathrm{NMR}$ spectra of PVPyOzP- $b$-PAN synthesized via sequential anionic polymerization. (Entry 07 in Table 3, Insert shows small portion of PVPyOzP in block copolymer of PVPyOzP- $b$-PAN) 

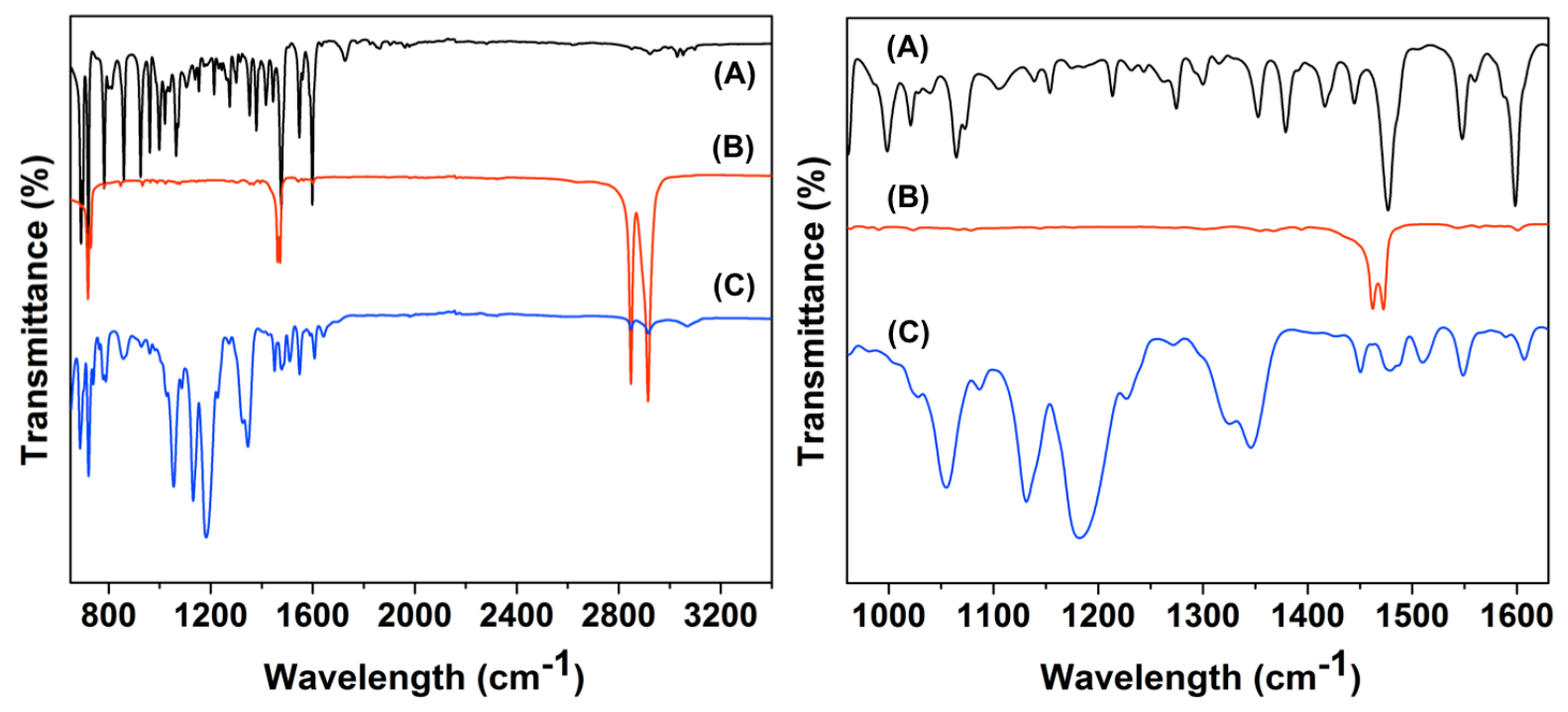

Figure S10. FT-IR spectra of (A) parent VPyOzP, (B) QVPyOzP [I], and (C) QVPyOzP $\left[\mathrm{Tf}_{2} \mathrm{~N}\right]$ with range of wavelength from 670 to 3340 on the left and from 950 to $1650 \mathrm{~cm}^{-1}$ on the right. 


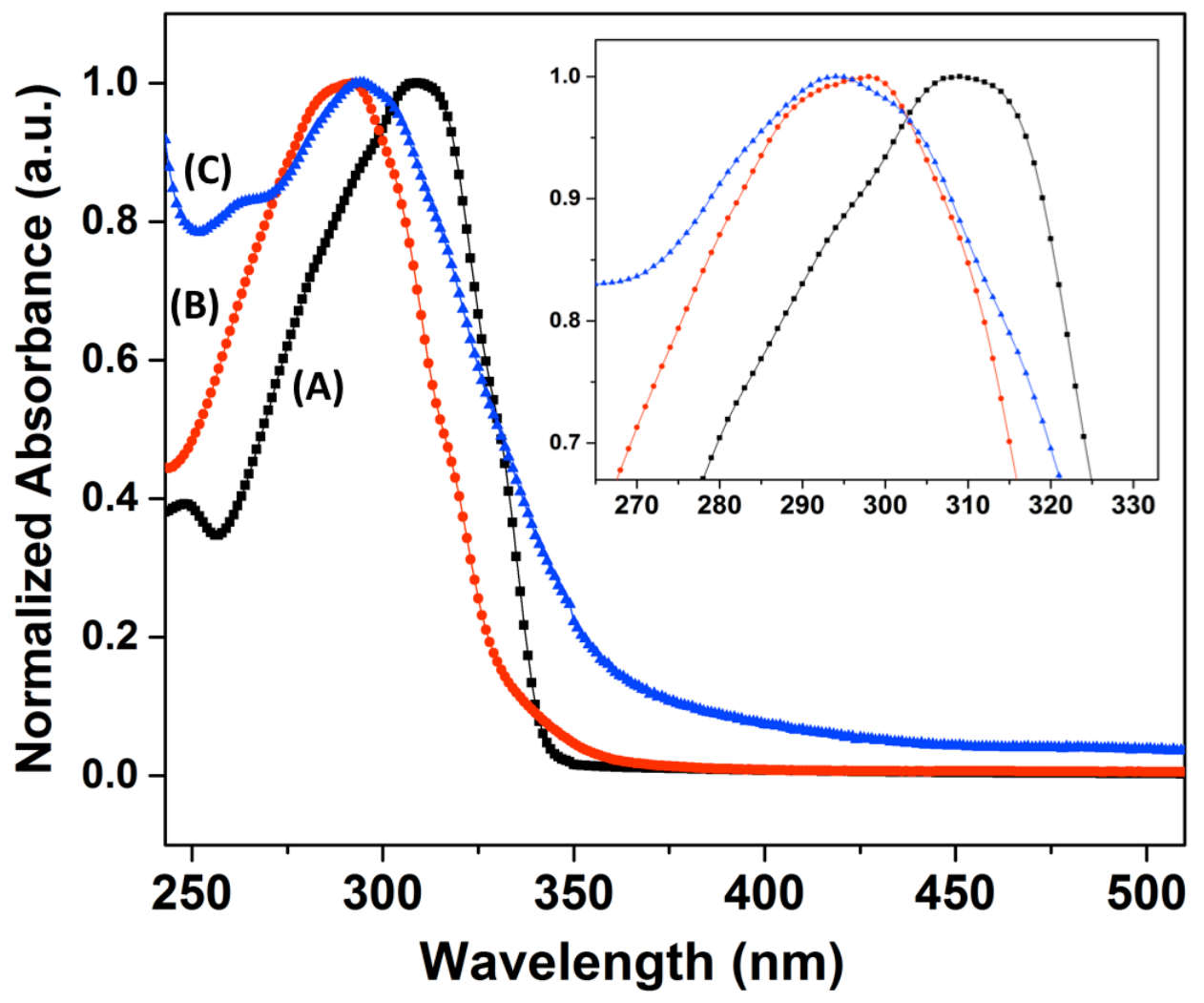

Figure S11. UV-Vis spectra of (A) parent VPyOzP, (B) QVPyOzP [I], and (C) QVPyOzP $\left[\mathrm{Tf}_{2} \mathrm{~N}\right]$. The insert shows the UV-Vis spectra of $(\mathrm{A}),(\mathrm{B})$, and $(\mathrm{C})$ in the range from 250 to $324 \mathrm{~nm}$. 


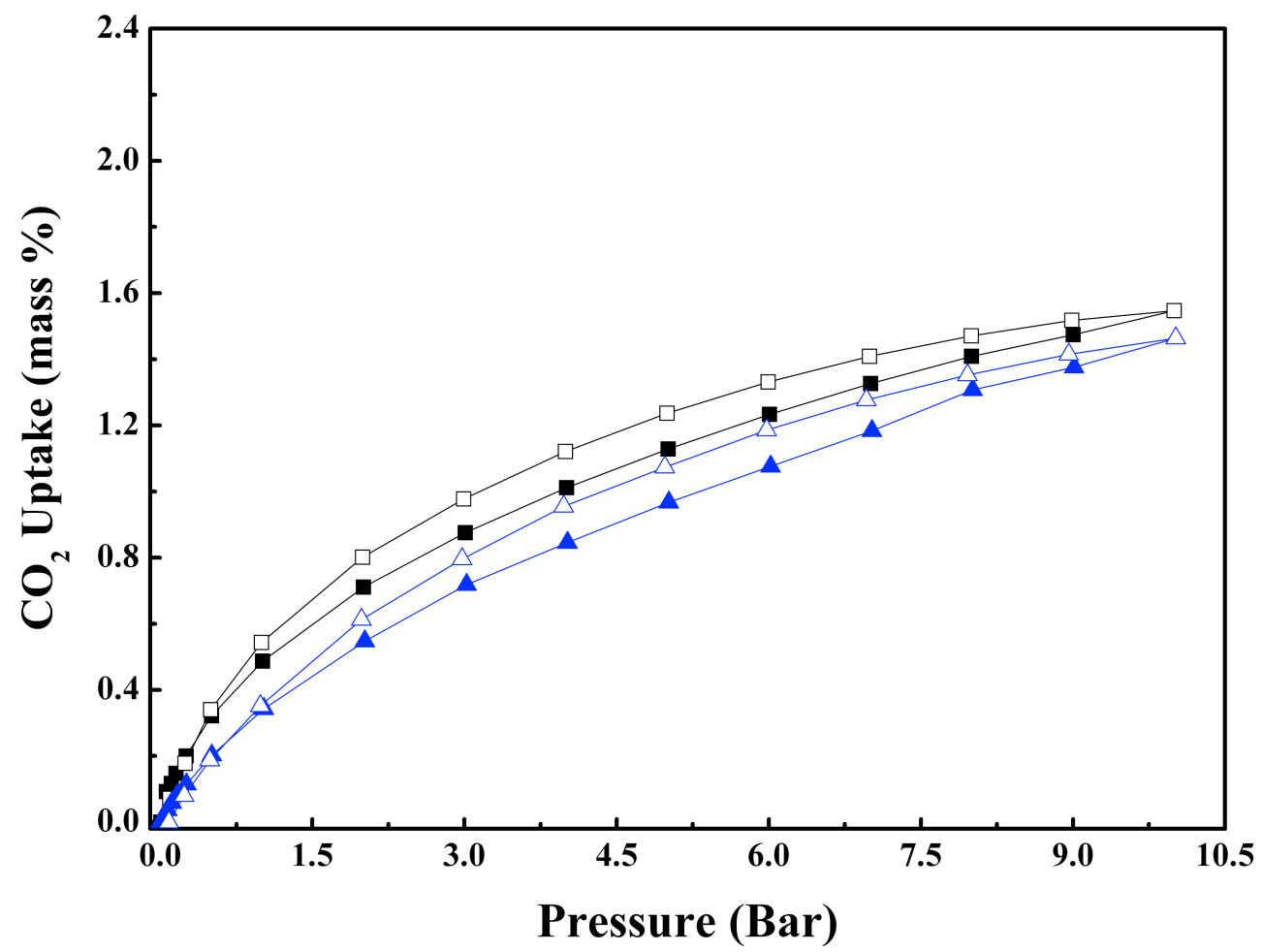

Figure S12. $\mathrm{CO}_{2}$ adsorption (closed symbols) and desorption (open symbols) of QVPyOzP with iodide anion $\left(\mathrm{I}^{-}\right.$, squares $)$and triflate anion $\left(\mathrm{Tf}_{2} \mathrm{~N}^{-}\right.$, triangles $)$. 


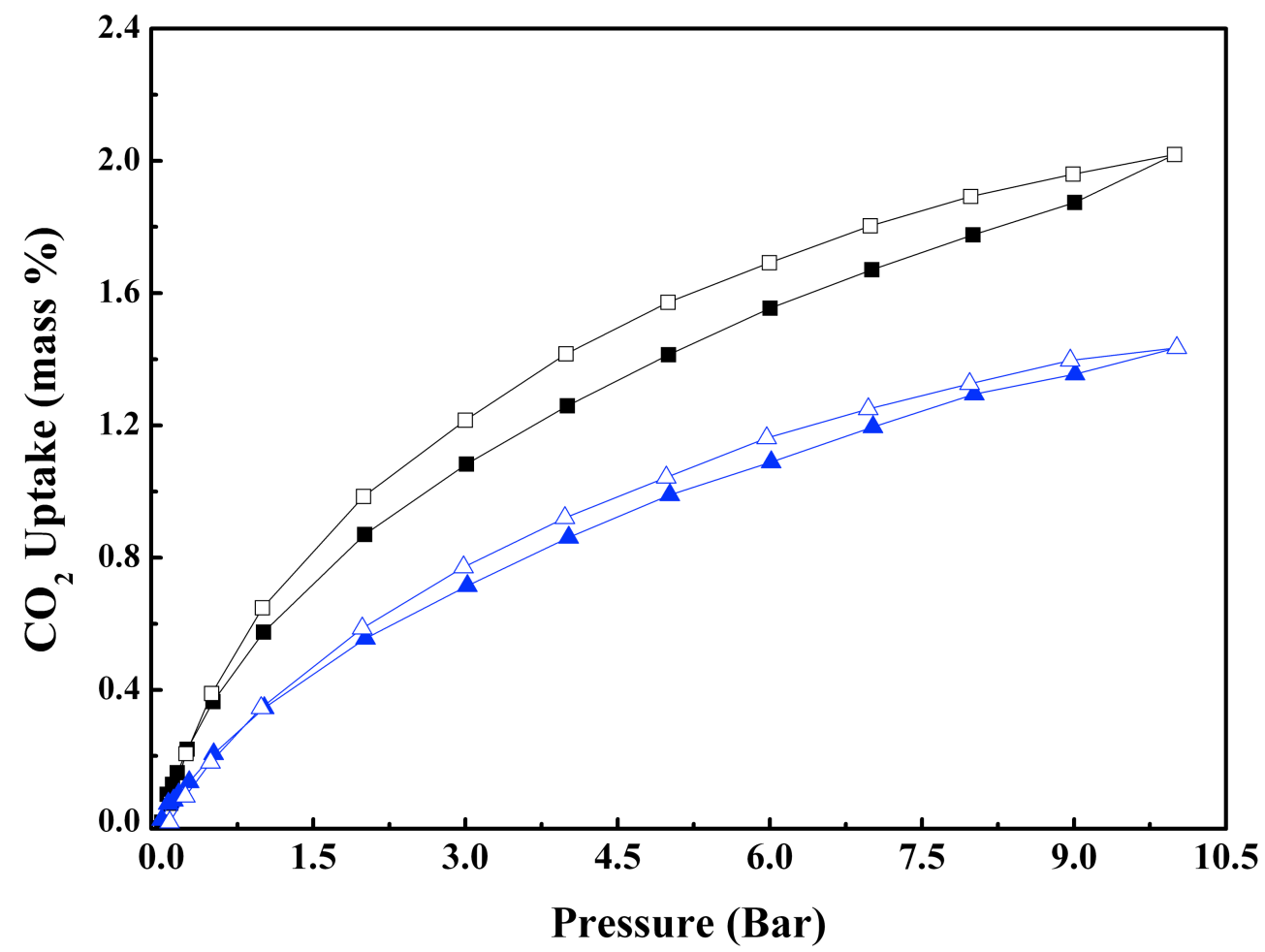

Figure S13. $\mathrm{CO}_{2}$ adsorption (closed symbols) and desorption (open symbols) of PQVPyOzP with iodide anion $\left(\mathrm{I}^{-}\right.$, squares $)$and triflate anion $\left(\mathrm{Tf}_{2} \mathrm{~N}^{-}\right.$, triangles). 